Communications in Physics, Vol.31, No. 1 (2021), pp. 95-102

DOI:10.15625/0868-3166/15558

\title{
REMOVAL OF RHODAMINE B DYE BY PLASMA JET OXIDATION PROCESS
}

\author{
LE THI QUYNH XUAN ${ }^{1,2,+}$, TRAN HONG QUAN ${ }^{1,2,+}$, TRINH THU HA ${ }^{3}$ \\ AND DAO NGUYEN THUAN ${ }^{1, \dagger}$ \\ ${ }^{1}$ Laboratory of Plasma Technology, Institute of Materials Sciences (IMS), Vietnam Academy of \\ Science and Technology (VAST), Hanoi, Vietnam \\ ${ }^{2}$ Graduate University of Science and Technology (GUST), VAST \\ ${ }^{3}$ Laboratory of Environmental and Bioorganic Chemistry, Institute of Chemistry, VAST \\ E-mail: ${ }^{\dagger}$ thuandn@ims.vast.ac.vn \\ + These authors contributed equally to this work.
}

Received 2 October 2020

Accepted for publication 23 November 2020

Published 05 April 2021

\begin{abstract}
Recently, nonthermal atmospheric pressure plasma has been developed as a novel tool in removal of water pollutants. Rhodamine $B$ dye, widely used in textiles and biology, is toxic to both humans and animals, hence removing residual Rhodamine $B$ in solution is necessary. In this work, we set up a cold plasma jet system and used it to effectively remove Rhodamine $B$ in the solution. We showed that the main oxidation substance responsible to remove Rhodamine $B$ is the hydroxyl radical $(\bullet \mathrm{OH})$. By studying the effects of - the hydrogen peroxide $\left(\mathrm{H}_{2} \mathrm{O}_{2}\right)$ concentration in the initial and later produced in the solution, the plasma power, and the Ar gas flow speed-on the dye remove rate, we identified 2 main reaction pathways to generate hydroxyl radical $(\bullet \mathrm{OH})$. Both of these reaction pathways involved high-energy electrons interacting with water and $\mathrm{O}_{2}$ in the solution and in the ambient air. Our work provided important information to understand the mechanism of dye removal by cold plasma treatment.
\end{abstract}

Keywords: cold plasma, plasma jet, oxidation, organic dye removal, Rhodamine B.

Classification numbers: 52.77.-j; 82.30.Lp; 81.65.Mq; 82.80.Dx.

\section{INTRODUCTION}

The organic dyes, have been widely used in the textile industry for decades, are known as toxic and polluted compounds because of their high persistence in soil and water resources. Rhodamine B dye, belonging to the class of Xanthene, is used as a colorant in textiles and a staining (C)2021 Vietnam Academy of Science and Technology 
in biology. It can cause skin irritation, eyes and respiratory infection, chronic and neuro toxicity in both humans and animals, thus demanding in removing residue Rhodamine B in solution is inevitable [1]. Recent works on removing Rhodamine B pay a great attention to advanced oxidation technologies, including photocatalysis [2] and plasma treatment [3-5].

Non-thermal atmospheric pressure plasma (ATP) has been developed as a novel tool in removal of water pollutants [6] owing to its advantages of working in daily life conditions, quick and energy efficient. Atmospheric plasma produces a great amount of reactive oxygen species (ROS), high energy particles (electrons and ions). Various ROS species as hydroxyl radical $(\bullet \mathrm{OH})$, hydrogen peroxide $\left(\mathrm{H}_{2} \mathrm{O}_{2}\right)$, ozone $\left(\mathrm{O}_{3}\right)$, hydroperoxyl radical $\left(\bullet \mathrm{HO}_{2}\right)$ generated by plasma processes can acts as strong oxidizers to remove organic dyes [7-13]. Although many researches have suggested $\bullet \mathrm{OH}$ as one of the main oxidation substances, its generation pathways [8-12] as well as its conversion reactions $[8,9]$, during cold plasma interaction with solution, are complicated and remain unclear.

In this work, a plasma jet system was set up for removal of organic dye and demonstrated its operating in removing Rhodamine $\mathrm{B}$. We quantified the amount of $\bullet \mathrm{OH}$ and $\mathrm{H}_{2} \mathrm{O}_{2}$ generating during plasma processes by UV-VIS absorption and chemical measurements, and identified $\bullet \mathrm{OH}$ as the key oxidation substance. By studying effect of - the hydrogen peroxide $\left(\mathrm{H}_{2} \mathrm{O}_{2}\right)$ concentration in the initial and later generating in the solution, the plasma power, and the Ar gas flow speed - on the dye remove rate, we proposed there were only 2 main reaction pathways to generate $\bullet \mathrm{OH}$.

\section{EXPERIMENT}

\section{II.1. Materials}

Rhodamine B ( $\geq 95 \%)$ was purchased from Sigma Aldrich (SKU: 6626) and hydrogen peroxide $\mathrm{H}_{2} \mathrm{O}_{2}(30 \%)$ was purchased from Xilong Scientific Co., Ltd. Rhodamine B was diluted in double distilled water to a concentration of $50 \mathrm{mg} / \mathrm{l}$ and $10 \mathrm{ml}$-sample was used for each plasma treatment experiment.

\section{II.1.1. Setup of the plasma jet system for removal of Rhodamine B}

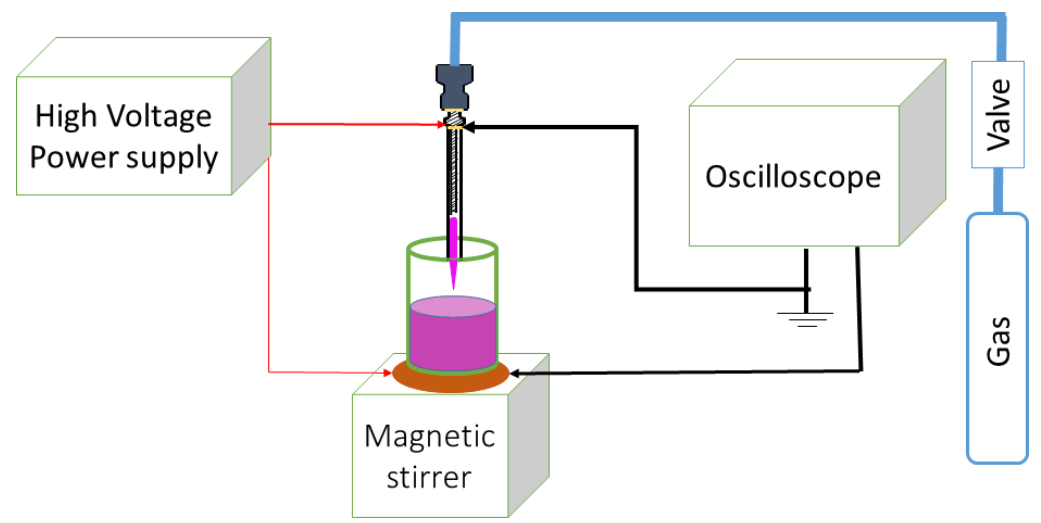

Fig. 1. Experiment setup of the plasma jet system for removal of Rhodamine B. 
The schematic representation of the plasma jet system for removal of Rhodamine B is shown in Fig. 1. A high frequency, high voltage power supply was applied between a needle electrode (inside a 5cm-length quartz tube) and a copper plate (below a beaker containing dye solution) to generate non-thermal plasma [14]. The Argon gas was fed through the needle with a gas flow rate of 4-8 L/minute. A stable plasma jet with a length of $1.5-2 \mathrm{~cm}$ could be achieved at output voltage $\sim 3-6 \mathrm{kV}$ and oscillating frequency $\sim 55 \mathrm{KHz}$. Distance from the plasma head to the Rhodamine B solution was $0.5 \mathrm{~cm}$. A magnetic stirrer was used to stir the Rhodamine B solution at $450 \mathrm{rpm}$ to ensure even plasma treatment. A high voltage probe and a micro current probe were connected to a Tektronix TBS1154 oscilloscope to measure the applied voltage and the discharged current, respectively. We integrated the multiply of the discharged current and voltage over a duty cycle to obtain a Lissajous plot and used it to calculate dissipated power of the plasma system [15].

\section{II.1.2. UV-VIS absorption spectroscopy}

UV-VIS absorption measurements were performed with a quartz cuvette with an optical path length of $10 \mathrm{~mm}$ and a sample volume of at least $300 \mu \mathrm{l}$. A single-beam Ocean Optics system included a DH-2000-BAL light source, a cuvette holder and a USB4000 spectrometer connected by optical fibers. Typically, 300-500 $\mu 1$ solution after plasma treatment was loaded to the quartz cuvette, which was put in the cuvette holder. The beam, which was generated by the UV-VIS light source, passed through the sample and the transmitted light was collected and driven into the spectrometer. The Oceanview software were used to control the spectrometer and acquire data with an integration time of $500 \mathrm{~ms}$. Three continuous scans were acquired and averaged to give an absorption spectrum in all cases.

\section{II.1.3. Detection and quantification of $\mathrm{H}_{2} \mathrm{O}_{2}$}

We used two methods to detect and measure $\mathrm{H}_{2} \mathrm{O}_{2}$ concentration: (1) monitoring absorption peak at $230 \mathrm{~nm}$ and using Beer-Lambert's law to calculate; (2) monitoring decolorization of $\mathrm{KMnO}_{4} 0.1 \mathrm{~N}$ when titrating to $\mathrm{H}_{2} \mathrm{O}_{2}$ solution to estimate the amount of $\mathrm{H}_{2} \mathrm{O}_{2}\left(1 \mathrm{ml} \mathrm{KMnO}_{4} 0.1 \mathrm{~N}\right.$ corresponds to $1.7 \mathrm{mg} \mathrm{H}_{2} \mathrm{O}_{2}$ ).

\section{RESULTS AND DISSCUSION}

\section{III.1. Removal of Rhodamine B by plasma jet treatment}

\section{III.1.1. Decolorization and degradation of Rhodamine $B$}

Figure 2 demonstrates that $10 \mathrm{ml}$ of Rhodamine B (50 mg/l) (Fig. 2(A)) can be removed by 24 minutes plasma treatment. The solution after plasma treatment was completely transparent and no residue remained on the inner side of the beaker (Fig. 2(B)). Fig. 2(C) shows absorption spectra of the Rhodamine B solution in a broad range from $220 \mathrm{~nm}$ to $700 \mathrm{~nm}$, before (0 minute) and after (24 minutes) plasma treatment. The absorption peak of Rhodamine B solution at 554 $\mathrm{nm}$ is due to $n \rightarrow \pi^{*}$ transitions of $(C=O, C=N)$ that yield the color of the solution. And the absorption peak at $259 \mathrm{~nm}$ is due to $\pi \rightarrow \pi^{*}$ transitions of the aromatic ring groups that yield the aromatic content of the solution [7,8]. We observed only $\mathrm{H}_{2} \mathrm{O}_{2}$ absorption peak at $230 \mathrm{~nm}$ from Rhodamine B solution after 24 minutes plasma treatment, that confirmed the dye was completely removed. Because the absorption peak at $259 \mathrm{~nm}$ of the aromatic ring could be interfered by $\mathrm{H}_{2} \mathrm{O}_{2}$ 
absorption peak at $230 \mathrm{~nm}$, we used the absorption peak at $554 \mathrm{~nm}$ to monitor the Rhodamine B removal effect of our plasma treatment.

A

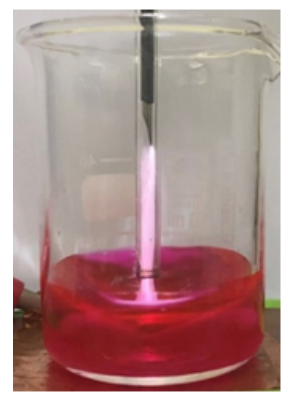

B

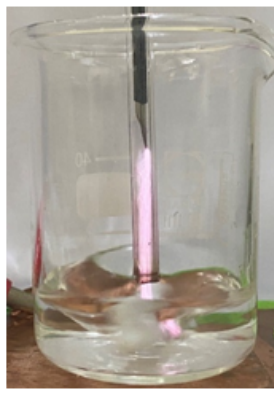

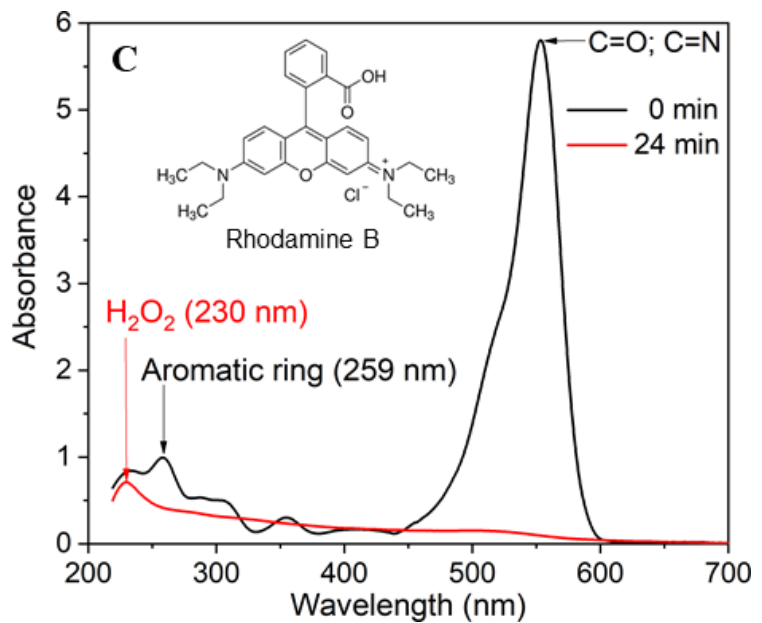

Fig. 2. Picture of $10 \mathrm{ml}$ Rhodamine $B(50 \mathrm{mg} / \mathrm{l})$ solution (A) before plasma treatment and (B) after 24-minutes plasma treatment. (C) Absorption spectra of Rhodamine B (0 min, black curve) before and ( $24 \mathrm{~min}$, red curve) after plasma treatment. The inset is the chemical structure of Rhodamine B.

\section{III.1.2. Removal rate of Rhodamine B by plasma jet}
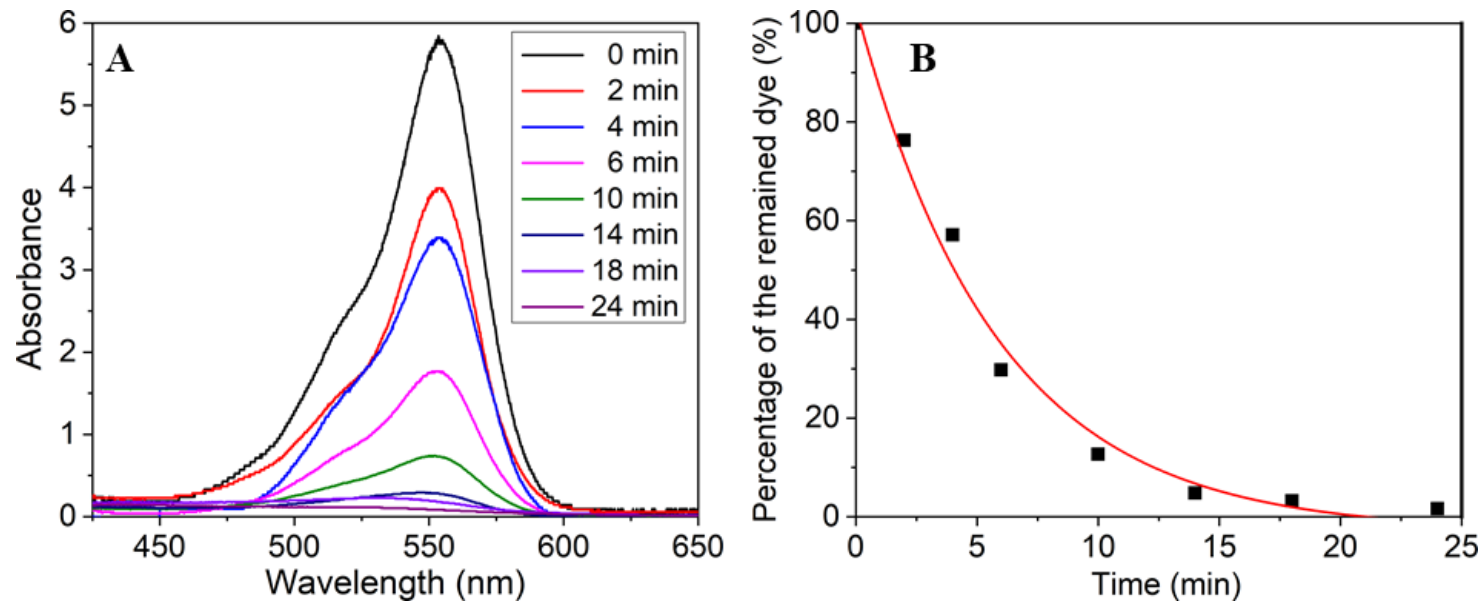

Fig. 3. (A) Dependence of the absorption band of Rhodamine B at $554 \mathrm{~nm}$ on plasma treatment time. (B) Percentage of the remained dye (black dots) as a function of plasma treatment time and the fitting (red curve) by a first-order reaction kinetic.

To determine the efficiency of removing Rhodamine B by plasma treatment, we measured the absorption band of Rhodamine B around $554 \mathrm{~nm}$ at different plasma treatment time (Fig. 3(A)). 
We estimated the percentage of the remained dye by the ratio of the integrated area in absorption spectrum (from $450 \mathrm{~nm}$ to $600 \mathrm{~nm}$ ) between a particular treatment time and before plasma treatment (Fig 3(B)). Typically, the dependence of the concentration of remained dye on the oxidation treatment time can be described by a first-order reaction kinetic [10] as:

$$
C=C_{0} e^{-k t},
$$

with $C_{0}$ is the initial dye concentration, $C$ is the dye concentration after $t$ minutes treatment time and $k$ is the rate constant. Fitting our data in figure $3 \mathrm{~B}$ with an exponential decay gave $k=0.18$ with the coefficient of determination $R^{2}=0.98$.

\section{III.2. Mechanism of the Rhodamine B degradation process by plasma jet}

\section{III.2.1. Hydroxyl radical $(\bullet \mathrm{OH})$ is the crucial oxidation substance}

In most oxidation process of organic dye by plasma discharge, the hydroxyl radical $(\bullet \mathrm{OH})$ has been shown to be one of the main oxidation factors $[3,9,13,16]$. The hydroxyl radical $(\bullet \mathrm{OH})$, which is the neutral form of the hydroxide ion $(\mathrm{OH}-)$, is highly reactive and consequently shortlived. Various reaction pathways to generate $\bullet \mathrm{OH}$ by plasma processes have been reported [8-12] and can be summarized as following:

$$
\begin{aligned}
* \mathrm{e}+\mathrm{H}_{2} \mathrm{O} & \longrightarrow \cdot \mathrm{OH}+\cdot \mathrm{H}+\mathrm{e} \\
3 \mathrm{O}_{3}+\mathrm{H}_{2} \mathrm{O} & \longrightarrow 2 \cdot \mathrm{OH}+4 \mathrm{O}_{2} \\
\mathrm{H}_{2} \mathrm{O}_{2}+2 \mathrm{O}_{3} & \longrightarrow 2 \cdot \mathrm{OH}+3 \mathrm{O}_{2} \\
\mathrm{H}_{2} \mathrm{O}_{2}+* \mathrm{e} & \longrightarrow 2 \cdot \mathrm{OH}+\mathrm{e}
\end{aligned}
$$

with $* e$ is the high-energy electron.

Those $\bullet \mathrm{OH}$ generation pathways can be divided in 2 groups: directly (Eq. (2)) when the high energy electrons from plasma interact with water in the solution; or indirectly (Eqs. (3)-(5)) through intermediate products like Ozone $\left(\mathrm{O}_{3}\right)$ or hydrogen peroxide $\left(\mathrm{H}_{2} \mathrm{O}_{2}\right)$. The $\mathrm{O}_{3}$ in Eqs. (3) and (4) are produced by these reactions:

$$
\begin{aligned}
& * \mathrm{e}+\mathrm{O}_{2} \longrightarrow 2 * \mathrm{O}+\mathrm{e}, \\
& * \mathrm{O}+\mathrm{O}_{2} \longrightarrow \mathrm{O}_{3},
\end{aligned}
$$

with $* O$ is the high-energy oxygen atom.

Meanwhile, parts of the hydroxyl radical $(\bullet \mathrm{OH})$ can be converted to hydrogen peroxide $\left(\mathrm{H}_{2} \mathrm{O}_{2}\right)$ and hydroperoxyl radical $\left(\bullet \mathrm{HO}_{2}\right)$ at different reaction rates $[8,11,17]$ as:

$$
\begin{gathered}
\cdot \mathrm{OH}+\cdot \mathrm{OH} \stackrel{k_{1}}{\longrightarrow} \mathrm{H}_{2} \mathrm{O}_{2}, \mathrm{k}_{1}=5.5 * 10^{9} \mathrm{M}^{-1} \mathrm{~s}^{-1}, \\
\mathrm{H}_{2} \mathrm{O}_{2}+\cdot \mathrm{OH} \stackrel{k_{2}}{\longrightarrow} \cdot \mathrm{HO}_{2}+\mathrm{H}_{2} \mathrm{O}, k_{2}=2.7 * 10^{7} \mathrm{M}^{-1} \mathrm{~s}^{-1} .
\end{gathered}
$$

Since $k_{1}$ is two orders of magnitude higher than $k_{2}$, reaction in Eq. (8) happens at much slower rate than reaction in Eq. (9). However, $\bullet \mathrm{HO}_{2}$ radical is much less reactive than $\bullet \mathrm{OH}$, hence increasing $\bullet \mathrm{HO}_{2}$ should result in a negligible contribution to the dye removal rate [8].

\section{III.2.2. Hydrogen peroxide $\left(\mathrm{H}_{2} \mathrm{O}_{2}\right)$ generation by plasma jet}

Although the hydroxyl radical $(\bullet \mathrm{OH})$ has been proved as one of the main oxidation agent to remove dye in plasma treatment $[3,9,13,16]$, the contribution of each reaction pathway to generate $\bullet \mathrm{OH}$ (Eqs. (2)-(5)) has not yet been determined. Since reactions in Eqs. (4) and (5) 
require hydrogen peroxide $\left(\mathrm{H}_{2} \mathrm{O}_{2}\right)$, we quantified amount of $\mathrm{H}_{2} \mathrm{O}_{2}$ produced in the solution by plasma and investigated the effect of $\mathrm{H}_{2} \mathrm{O}_{2}$ concentration on the dye removal rate.
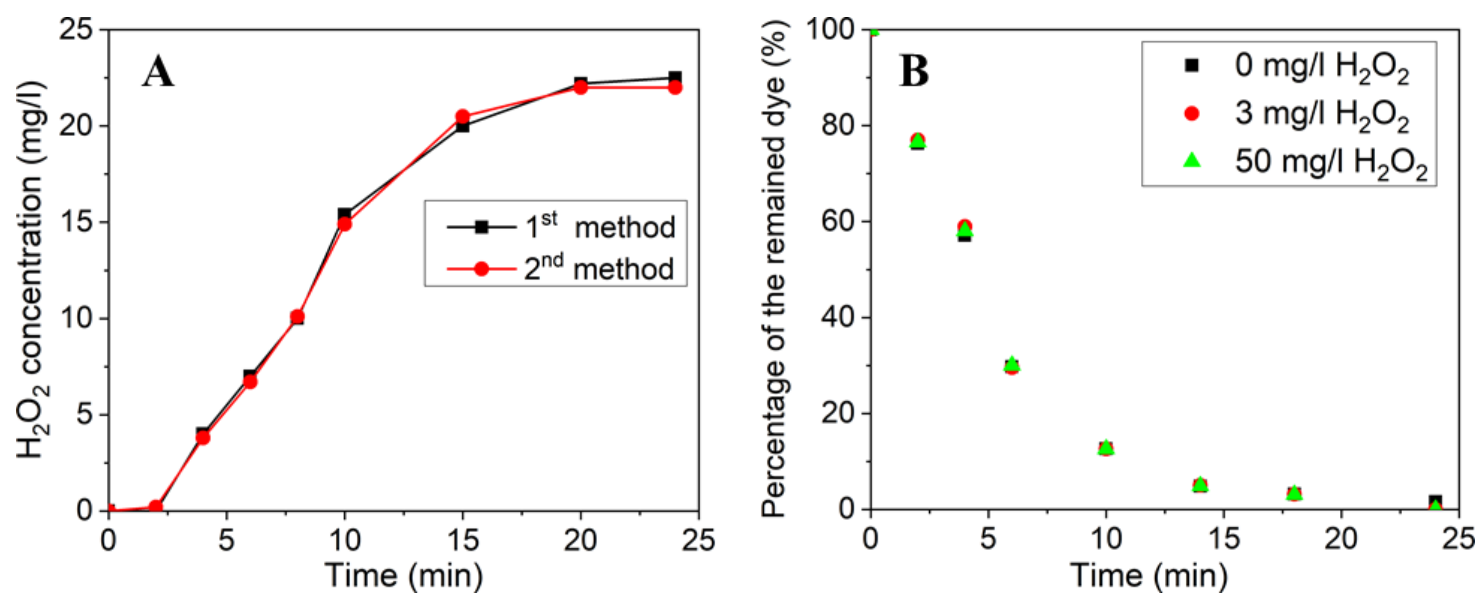

Fig. 4. (A) Hydrogen peroxide $\left(\mathrm{H}_{2} \mathrm{O}_{2}\right)$ concentration detected by 2 different methods after several plasma treatment time. (B) Plot of percentage of the remained dye as a function of plasma treatment time in 3 different initial $\mathrm{H}_{2} \mathrm{O}_{2}$ concentration.

We employed 2 methods to quantify $\mathrm{H}_{2} \mathrm{O}_{2}$ in the solution as described in the Method section. The first one used the absorption peak at $230 \mathrm{~nm}$ while the second one used titration to decolorize certain amount of $\mathrm{KMnO}_{4}$. Figure 4A shows a very good agreement between these 2 methods to quantify amount of $\mathrm{H}_{2} \mathrm{O}_{2}$ generated in the solution by the plasma jet. The $\mathrm{H}_{2} \mathrm{O}_{2}$ concentration increased with plasma treatment time and was saturated at $22 \mathrm{mg} / \mathrm{l}$ after $24 \mathrm{~min}$ utes. The $\mathrm{pH}$ of the solution (measured by an ADWA AD11 pH meter with the error \pm 0.1 ) also changed from 7.0 to 4.5 due to the amount of $\mathrm{H}_{2} \mathrm{O}_{2}$ present in the solution. These results validated the reaction in Eq. (8).

We performed plasma treatment experiments with 3 different concentrations of the initial hydrogen peroxide $\left(\mathrm{H}_{2} \mathrm{O}_{2}\right): 0,3$ and $50 \mathrm{mg} / \mathrm{l}$ to study effect of $\mathrm{H}_{2} \mathrm{O}_{2}$ on the reaction rate. Figure $4 \mathrm{~B}$ shows that the reaction rate is independence of the initial $\mathrm{H}_{2} \mathrm{O}_{2}$ concentration, hence reactions in Eqs. (4) and (5) contribute very little to the $\bullet \mathrm{OH}$ generation during plasma treatment. These results agree with previous work by Daneshvar and co-authors, where $\mathrm{H}_{2} \mathrm{O}_{2}$ only reacted efficiently with Rhodamine B under a strong UV radiation $\left(5-30 \mathrm{~W} / \mathrm{m}^{2}\right)$ [8]. The UV power measured at a distance of $5 \mathrm{~mm}$ from our plasma nozzle was only $0.3 \mathrm{~W} / \mathrm{m}^{2}$.

By excluding reactions in Eqs. (4) and (5), we can validate the only pathways to generate the hydroxyl radical $(\bullet \mathrm{OH})$ are reactions in Eqs. (2) and (3). The direct reaction in Eq. (2) requires only high-energy electron $* e$ reacting with water, while the indirect reaction in Eq. (3) requires Ozone $\left(\mathrm{O}_{3}\right)$, an intermediate substance produced by $* e$ reacting with Oxygen $\left(\mathrm{O}_{2}\right)$ in ambient air and inside the solution. To resolve how much each reaction contributes to the amount of $\bullet \mathrm{OH}$ generation during plasma treatment, further works including mixing additional Oxygen gas or employing an scavenger substance [12] need to be done. 

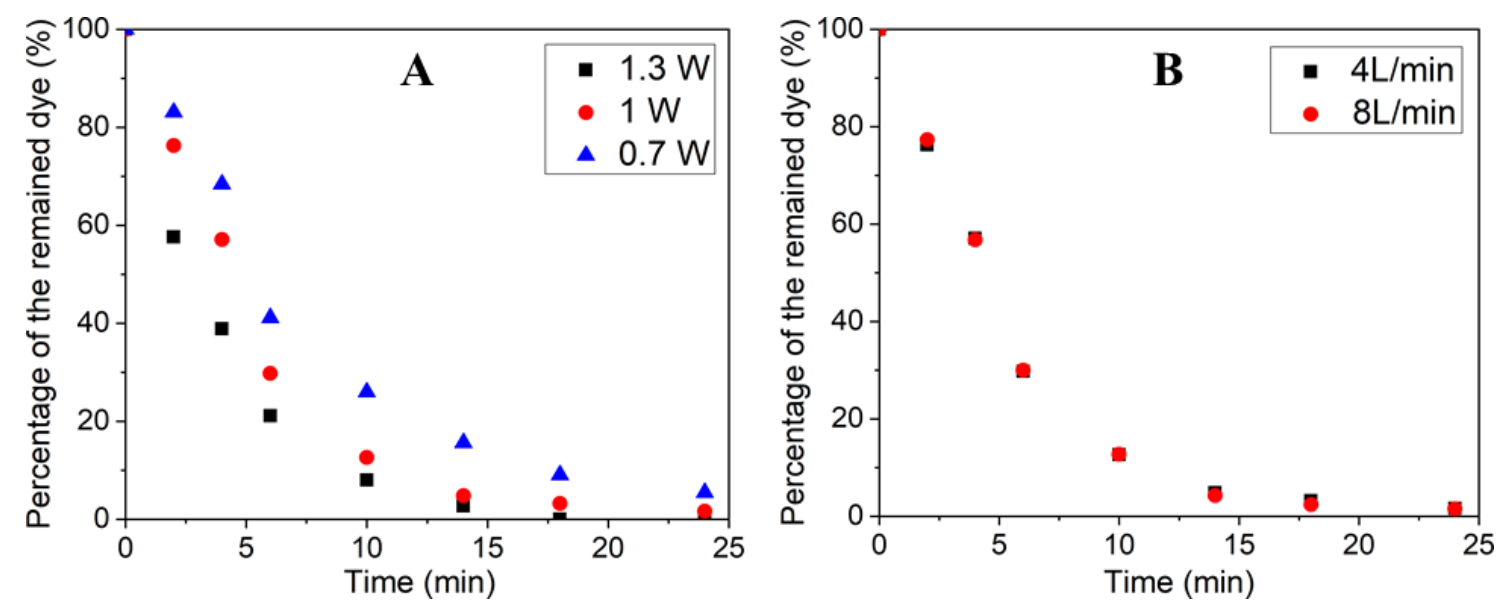

Fig. 5. Comparison of the Rhodamine $B$ removal rate at (A) different plasma powers: 1.3, 1 and $0.7 \mathrm{~W}$; and (B) different gas flow speed: 4 and $8 \mathrm{~L} / \mathrm{min}$.

\section{III.3. Effect of the plasma power and Ar gas flow speed}

To find an optimal condition for Rhodamine B removal by plasma treatment, we studied the effect of the plasma power and the gas flow speed on the removal rate. Figure 5A shows that the removal rate increases linearly with the plasma power: the rate constants are $0.24 \mathrm{~min}^{-1}, 0.18$ $\mathrm{min}^{-1}$ and $0.13 \mathrm{~min}^{-1}$ with plasma power of $1.3 \mathrm{~W}, 1 \mathrm{~W}$ and $0.7 \mathrm{~W}$ (Table 1 ), respectively. This effect also is in agreement with reactions in Eqs. (2) and (3), since both these reaction pathways require high-energy electron $* e$. The amount of high-energy electron $* e$ generated by plasma jet should be linear with the plasma power. Although higher plasma power will lead to faster dye removal rate, the heating problem and instability of the power supply will limit the actual operating power.

Table 1. Dependence of the percentage of the remained dye after 10 minutes plasma treatment, the rate constant and the coefficient of determination $\mathrm{R}^{2}$ versus the plasma powers.

\begin{tabular}{cccc}
\hline $\begin{array}{c}\text { Plasma } \\
\text { power } \\
(\mathrm{W})\end{array}$ & $\begin{array}{c}\text { Percentage of the remained } \\
\text { dye after 10 minutes } \\
\text { plasma treatment }(\%)\end{array}$ & $\begin{array}{c}\text { Rate } \\
\text { constant } \\
k\left(\min ^{-1}\right)\end{array}$ & $\mathrm{R} 2$ \\
\hline \hline 1.3 & 8 & 0.24 & 0.99 \\
1 & 13 & 0.18 & 0.98 \\
0.7 & 26 & 0.13 & 0.98 \\
\hline
\end{tabular}

Figure 5(B) shows that the Ar gas flow speed (4 and $8 \mathrm{~L} / \mathrm{min}$ ) does not affect the dye removal rate. This result is in agreement not only with previous work [18], but also with the reactions in Eqs. (2) and (3). Both these reactions are independent of the Ar gas flow rate. 


\section{CONCLUSION}

We set up a cold plasma jet system for dye removal and demonstrated it effect in removing Rhodamine B by plasma treatment. $10 \mathrm{ml}$ of Rhodamine B $(50 \mathrm{mg} / \mathrm{l})$ could be removed completely by 24 minutes plasma treatment with $1 \mathrm{~W}$ plasma power. We showed that the main oxidation substance to remove Rhodamine B was hydroxyl radical $(\bullet \mathrm{OH})$ generated by plasma. By studying the effect of - the hydrogen peroxide $\left(\mathrm{H}_{2} \mathrm{O}_{2}\right)$ concentration in the initial and later generated in the solution, the plasma power, and the Ar gas flow speed - on the dye remove rate, we identified 2 main reaction pathways (Eqs (2) and (3)) to generate hydroxyl radical $(\bullet \mathrm{OH})$. Both of these reaction pathways involved high-energy electrons interacting with water and $\mathrm{O}_{2}$ in the solution and in the ambient air. Our work provided important information to understand the mechanism of dye removal by cold plasma treatment.

\section{ACKNOWLEDGMENT}

This research was supported by Institute of Materials Sciences (IMS), Vietnam Academy of Science and Technology (VAST) under grant number HTCBT.04/20-20, and by Vingroup Joint Stock Company and supported by the Domestic Master/ PhD Scholarship Programme of Vingroup Innovation Foundation (VINIF), Vingroup Big Data Institute (VINBIGDATA) for Le Thi Quynh Xuan.

\section{REFERENCES}

[1] Jain, R., M. Mathur, S. Sikarwar, and A. Mittal, J. Environ. Manage. 85 (2007) 956.

[2] Tariq, M., M. Muhammad, J. Khan, A. Raziq, M.K. Uddin, A. Niaz, S.S. Ahmed, and A. Rahim, J. Mol. Liq. 312 (2020) 113399.

[3] Victor Odhiambo, S. and N.N. Wilfrida, Advanced Oxidation Processes for Dye Removal From Wastewater, in Impact of Textile Dyes on Public Health and the Environment, W. Khursheed Ahmad, J. Nirmala Kumari, and B. Ajmal Rashid, Editors. 2020, IGI Global: Hershey, PA, USA. p. 205.

[4] F. Tampieri, A. Giardina, F. J. Bosi, A. Pavanello, E. Marotta, B. Zaniol, G. Neretti and C. Paradisi, Plasma Process. Polym. 15 (2018) 1700207.

[5] S. E. More, N. Dwivedi, S. Sable, D. S. Mane, S. R. Tapase, K. M. Kodam, S. V. Bhoraskar and V. L. Mathe, J. Environ. Chem. Eng. 8 (2020) 103783.

[6] Iervolino, G., V. Vaiano, and V. Palma, Sep. Purif. Technol. 215 (2019) 155.

[7] Muruganandham, M. and M. Swaminathan, Dyes and Pigments 62 (2004) 269.

[8] Daneshvar, N., M.A. Behnajady, M.K.A. Mohammadi, and M.S.S. Dorraji, Desalination 230 (2008) 16.

[9] Cuiping, B., X. Xianfeng, G. Wenqi, F. Dexin, X. Mo, G. Zhongxue, and X. Nian, Desalination 278 (2011) 84.

[10] Y. Chen, Y. Li, A. Zhu, Y. Huang, Z. Liu, and K. Yan, Environ. Sci. Pollut. Res. 21 (2014) 9948.

[11] P. Attri, Y. H. Kim, D. H. Park, J. H. Park, Y. J. Hong, H. S. Uhm, K.-N. Kim, A. Fridman and E. H. Choi, Sci Rep-Uk 5 (2015) 9332.

[12] M. M. Ali, J. S. Arya Nair, and K.Y. Sandhya, Dyes and Pigments 163 (2019) 274.

[13] X. Ding, L. Gutierrez, J.-P. Croue, M. Li, L. Wang and Y. Wang, Chemosphere 253 (2020) 126655.

[14] Hong, Y., N. Lu, J. Pan, J. Li, Y. Wu, and K. Shang, IEEE Trans. Plasma Sci. 41 (2013) 545.

[15] L. N. Nguyen, N. Kaushik, P. Lamichhane, S. Mumtaz, R. Paneru, P. Bhartiya, J. S. Kwon, Y. K. Mishra, L. Q. Nguyen, N. K. Kaushik, and E. H. Choi, Green Chem. 22 (2020) 6588.

[16] B. P. Dojčinović, G. M. Roglić, B. M. Obradović, M. M. Kuraica, M. M. Kostić, J. Nešić and D. D. Manojlović, J. Hazard. Mater. 192 (2011) 763.

[17] G. V. Buxton, C. L. Greenstock, W. P. Helman and A. B. Ross, J. Phys. Chem. Ref. Data 17 (1988) 513.

[18] P. M. K. Reddy, B. R. Raju, J. Karuppiah, E. L. Reddy and C. Subrahmanyam, Chem. Eng. J. 217 (2013) 41. 